\title{
“A Matemática, Ela Assusta Um Pouco”: Crença De Autoeficácia E Mudança De Atitudes De Estudantes De Pedagogia A Partir Da Pesquisa Na Formação Inicial ${ }^{*}$
}

\author{
"Mathematics, It Scares A Little": Self-Effective Belief And Pedagogy \\ Students' Attitudes Change From Research In Initial Training
}

Klinger Teodoro Ciríaco

Universidade Federal de Mato Grosso do Sul - (UFMS - Câmpus de Naviraí)

Nelson Antonio Pirola

Universidade Estadual Paulista - (UNESP - Bauru)

\begin{abstract}
Resumo
Este artigo refere-se a uma investigação, em nível de pós-doutorado, na área da Psicologia da Educação Matemática, desenvolvida junto ao Programa de Pós-Graduação em Educação para Ciência da Universidade Estadual Paulista 'Júlio de Mesquita Filho' - UNESP/Bauru - que teve como objetivo compreender a mudança de atitude em relação à Matemática durante o processo de formação inicial de estudantes da licenciatura em Pedagogia a partir do contato com a pesquisa em Educação Matemática, em seus trabalhos de conclusão de curso (TCC's). $\mathrm{O}$ enquadramento teórico adotado aborda questões ligadas ao papel da pesquisa na formação do professor, crenças e atitudes, como também a aprendizagem da Matemática. A metodologia da pesquisa se inscreve no campo qualitativo em adotou-se a observação participante durante as orientações com as alunas da licenciatura e a narrativa como elemento estruturante da coleta e análise de dados com base em roteiros de entrevistas semiestruturados. Com a conclusão do estudo, foi possível perceber que a aproximação com as recomendações da literatura especializada da área, contribui para o desenvolvimento da autoeficácia, de atitudes positivas e da confiança em relação à Matemática, visando à construção da futura prática pedagógica.
\end{abstract}

Palavras-chave: Pesquisa em Educação Matemática. Atitudes. Autoeficácia. Formação de Professores.

\begin{abstract}
This article refers to an investigation, at the postdoctoral level, in the area of Mathematics Education Psychology, developed in the Post-Graduate Program in Education for Science of the Paulista State University 'Júlio de Mesquita Filho' - UNESP / Bauru - which aimed to understand the change in attitude about Mathematics during the undergraduate students in Pedagogy' process of initial training from the contact with the research in Mathematical Education in their studies of course completion. The theory adopted deals with questions related to the role of research in teacher education, beliefs and attitudes, as well as the learning of Mathematics. The methodology of the research is a qualitative approach in which it was adopted the participant observation during the orientation with the undergraduate students and the narrative as a structuring element of data collection and
\end{abstract}

\footnotetext{
* A opção de escrita adotada neste texto é a de primeira pessoa por entendermos que o exercício do estágio pósdoutoral envolve a compreensão mais autoral do texto, embora desenvolvido em parceria com o professor supervisor (segundo autor).
} 
analysis based on semi-structured interview scripts. With the conclusion of the study it was possible to perceive that the approximation with the recommendations of the specialized literature of the area, contributes to the development of self-efficacy, positive attitudes and confidence in Mathematics, aiming at the construction of future pedagogical practice.

Keywords: Research in Mathematics Education. Attitudes. Self efficacy. Teacher training.

\section{Introdução}

A aprendizagem da Matemática, assim como de qualquer outra disciplina escolar, é um processo complexo que envolve múltiplos fatores, além do cognitivo. Um deles diz respeito ao sentimento e crenças que as pessoas têm em relação à Matemática. Muitos alunos têm dificuldades nessa disciplina por apresentarem um comportamento de evitamento, resultado do desenvolvimento de pré-disposições negativas (atitudes) e de baixa crença em suas capacidades de aprender Matemática (autoeficácia) (AIKEN, 1970; BRITO; 1996; PIROLA, et al. 2015).

Neste contexto, esta investigação insere-se no campo da Psicologia da Educação Matemática em uma interlocução com a formação de professores na perspectiva de compreender em que medida o contato com a pesquisa sobre o ensino de Matemática, objeto de análise do trabalho de conclusão de curso (TCC) de acadêmicas de Pedagogia, contribui para a mudança de atitude e crença de autoeficácia das estudantes.

\section{Enquadramento Teórico/Problematização}

De acordo com Dobarro (2007), o campo da aprendizagem das Atitudes refere-se a uma vertente investigativa que busca compreender processos psicológicos, estrutura do indivíduo, bem como seu contexto social formativo e sua mudança de atitudes a partir da Psicologia da Influência Social.

De acordo com a autora, as atitudes dos sujeitos “[...] são processos psicológicos individuais, porém inseridas em um contexto de influência social. Em outras palavras, as atitudes são formadas por meio de processos psicológicos e sociais, na díade individualcoletivo" (DOBARRO, 2007, p. 23).

Brito (1996, p. 11) conceitua atitude como sendo uma “[...] disposição pessoal, idiossincrática, presente em todos os indivíduos, dirigida a objetos, eventos ou pessoas, que assume diferente direção e intensidade de acordo com as experiências do indivíduo". Para a autora, a atitude ainda apresenta componentes afetivos, cognitivos e motores (BRITO, 1996). 
A pesquisadora considera que as atitudes não são inatas, ou seja, elas são adquiridas “[...] embora algumas atitudes sejam mais duradouras e persistentes que outras, elas não são estáveis e variam ao longo da vida dos indivíduos, de acordo com circunstâncias ambientais" (BRITO, 1996, p. 12).

Aiken (1970, p. 551) define atitude como "[...] predisposição ou tendência de um indivíduo a responder positivamente ou negativamente a algum objeto, situação, conceito ou outra pessoa". Nessa direção, é desejável que a formação inicial no curso de Pedagogia leve em consideração a necessidade de contribuir para a aquisição de atitudes favoráveis em relação à Matemática, uma vez que, de acordo com Brito (1996, p. 146) “[...] para desenvolver atividades docentes adequadas, o indivíduo necessita apresentar atitudes positivas com relação ao ensino, à disciplina que vai ensinar, aos alunos e à própria escola”.

Seguindo esse raciocínio, cumpre salientar que a atividade do docente, por se tratar de uma dimensão também afetiva, gera influências na formação dos alunos, apresentando-se como um elemento relevante da sua prática (TORTORA; SANDER; PIROLA, 2013).

Pesquisas no campo da Psicologia da Educação Matemática (GONÇALEZ, 1995; MORON, 1998; ARDILES, 2007), apresentaram em suas conclusões que as atitudes dos professores em relação ao conhecimento matemático foram favoráveis, diferentemente do que se acreditava, isso porque a confiança dos sujeitos e a crença na própria capacidade de constituição de uma prática pedagógica diferenciada oportunizou um melhor desempenho profissional.

Pirola et. al. (2015) descreveram algumas experiências de estudos que apresentam contribuições das atitudes dos sujeitos em relação à Matemática. Para os autores, "[...] o professor que ensina Matemática deveria auxiliar os seus alunos a terem boas experiências com a Matemática escolar, o que desenvolveria atitudes positivas em relação a essa disciplina (PIROLA, et. al. 2015, p. 50)".

Moraes e Pirola (2015) afirmam que a formação de atitudes positivas em relação ao conhecimento matemático decorre das experiências com esse campo. Nessa perspectiva, se o futuro professor não teve, em sua trajetória, bons professores e boas recordações da Matemática, isso pode influenciar o modo como desenvolve sua prática, acarretando certo desconforto ao ter de abordar determinados conteúdos em sala de aula.

Além das atitudes, outro componente que possui forte influência na aprendizagem é a autoeficácia. A autoeficácia (BANDURA, 1986) dos professores contribuiu para a mudança de atitudes. O conceito de autoeficácia pode ser compreendido como “[...] um julgamento pessoal 
de capacidade relativa a um determinado domínio, e não se refere especificamente à capacidade de um indivíduo, mas sim ao que o mesmo acredita ser capaz de realizar, em uma variedade de circunstâncias" (SOUZA; BRITO, 2008, p. 195).

Estudos na área da Psicologia da Educação Matemática têm reforçado a premissa (DOBARRO; BRITO, 2010) de que as crenças de autoeficácia contribuem para a forma de sentir, pensar, motivar e de se comportar das pessoas.

A autoeficácia pode ainda ser entendida como sendo uma avaliação das competências para o desempenho de uma atividade determinada dentro de um contexto específico, como é o caso da abordagem conceitual da Matemática na formação inicial de professores.

Diferentes autores têm discutido sobre a influência que os acadêmicos recebem em suas vidas durante a escolarização básica por terem passado por experiências negativas com a Matemática (MOURA, 2005). Para Nacarato, Mengali e Passos (2009, p. 23) as futuras professoras "[...] trazem marcas profundas de sentimentos negativos em relação à disciplina, as quais implicam, muitas vezes, bloqueios para aprender e ensinar [...]” e é papel da formação inicial tentar desmistificar essa crença arraigada ao longo do processo formativo delas.

Thompson (1992) afirma que as crenças e preferências dos docentes sobre o conteúdo matemático e seu processo de ensino influenciam muito no padrão de estilo de docência adotado nas aulas. Nessa perspectiva, oportunizar o acesso à Matemática de forma menos traumática pode contribuir para a constituição de uma futura prática pedagógica que preza pela exploração das áreas de forma diferente com a que conviveram durante sua formação básica na escola enquanto alunos.

Estudos como os de Serrazina (2001) e Monteiro (2001) discutem essa questão destacando a formação de professores como sendo um ciclo inicial da escolaridade básica que, para os autores, corresponde aos anos inicias vivenciados na escola enquanto alunos. Com isso, destacam que o conhecimento necessário para ensinar Matemática inclui a compreensão de ideias fundamentais dos conceitos e seu papel no mundo atual.

Em um projeto de formação docente que incorpora princípios da autonomia, a relação teoria e prática e o processo de reflexão permanente sobre as ações são, necessariamente, elementos importantes no período inicial.

Com base na literatura especializada, pode-se afirmar que, a formação de atitudes positivas em relação à Matemática, tem influência dos processos formativos vivenciados pelos futuros professores no curso de licenciatura. Por essa razão, se o professor formador desenvolve uma prática na perspectiva de promoção do desenvolvimento de atitudes favoráveis frente à 
disciplina, as estudantes (futuras professoras) responderão aos estímulos por meio de experiências agradáveis, oportunizadas ainda pela aproximação do futuro professor com a pesquisa sobre o ensino de Matemática.

Frente à "fragilidade" da formação inicial para o ensino de Matemática, tão recorrente nos cursos dos quais professores da Educação Infantil e dos anos iniciais do Ensino Fundamental são egressos, tornam-se relevantes práticas de pesquisas que busquem caracterizar, de modo abrangente, quais implicações do contato com as recomendações da comunidade de educadores matemáticos para a mudança de atitudes e autoeficácia dos estudantes da licenciatura, neste caso a Pedagogia.

De maneira genérica, os cursos de formação de professores para os diferentes segmentos da Educação Básica têm sido realizados, muitas vezes, em instituições que não valorizam a prática investigativa, além de não manterem nenhum tipo de pesquisa, não estimulam o contato e não vislumbram o consumo dos produtos da investigação sistemática (CURI, 2004).

Para que haja uma mudança de concepção do sujeito em relação a sua atuação, uma das alternativas promissoras é o desenvolvimento de uma postura investigativa sobre o objeto de ensino, nesse caso a Matemática. Para que esse pressuposto ocorra, acredito e defendo a tese de que é por meio da pesquisa que o professor torna-se crítico-reflexivo, haja vista que ao ter a experiência de pesquisar, ele pode torna-se mais instintivo e autônomo em suas ações, pois passará a perceber o processo de ensino e aprendizagem em diferentes perspectivas, em que uma delas diz respeito às tarefas investigativas em suas aulas.

\section{Metodologia}

Elegeu-se, para a realização deste trabalho de pós-doutorado, uma metodologia de estudo qualitativa, de caráter descritivo-analítico, em que a utilização de narrativas orais e escritas foi o elemento central tanto da coleta quanto da análise de dados, por acreditar na possibilidade formativa/reflexiva que tal prática tem gerado no contexto da formação do professor (MARQUESIN; NACARATO, 2011).

Podemos dizer que estas são características gerais dos estudos com abordagem qualitativa. Assim, esse tipo de abordagem pode assumir diversas formas, cabendo ao pesquisador adequá-la à sua investigação.

O trabalho envolveu um mapeamento de estudantes da licenciatura em Pedagogia que estavam desenvolvendo seus respectivos trabalhos de conclusão de curso (TCC's), no campo 
da Educação Matemática, na Universidade Federal de Mato Grosso do Sul - UFMS, Câmpus Naviraí - durante o ano de 2016.

Adotou-se a narrativa oral durante sessões de entrevistas semiestruturadas a partir do movimento da orientação no processo de realização das pesquisas das alunas, uma vez que foram minhas orientandas na UFMS. No total, compuseram o corpus analítico do relatório de estágio pós-doutoral 5 (cinco) acadêmicas e, para este artigo, serão descritos 2 (dois) casos.

Assim, as narrativas das estudantes sobre o percurso da pesquisa de seus TCC's foram realizadas em dois momentos: a) no início da pesquisa e; b) ao final do processo investigativo. O roteiro das questões foi elaborado pensando na problematização da experiência de escrita sobre como organizam os procedimentos de estudos, as formas de compreensão das recomendações da literatura da área, importância da pesquisa na formação inicial de professores que ensinam Matemática, entre outros fatores que puderam auxiliar na percepção da mudança de atitude e crença de autoeficácia.

\subsection{Caracterização Das Futuras Professoras Participantes Da Pesquisa}

As participantes foram orientadas de trabalho de conclusão de curso do primeiro autor. Além de pesquisar questões ligadas ao ensino de Matemática no TCC, as alunas colaboradoras participavam, quando do momento da coleta de dados, do Programa Institucional de Bolsas de Iniciação à Docência - PIBID - do curso de Pedagogia ao qual estavam vinculadas.

Para além de terem cursado as disciplinas bases para a docência em Matemática na Educação Infantil e nos anos iniciais do Ensino Fundamental, optaram por desenvolver práticas de pesquisas relacionadas à Educação Matemática em seus estudos, como podemos verificar no quadro 1:

\begin{tabular}{|c|c|c|c|}
\hline ALUNA/IDADE & OBJETO DE PESQUISA & INÍCIO & FIM \\
\hline $\begin{array}{c}\text { Aritmética } \\
23 \text { anos }\end{array}$ & Ensino de número na Educação Infantil & Março/2016 & Março/2017 \\
\hline $\begin{array}{c}\text { Simetria } \\
33 \text { anos }\end{array}$ & Geometria na Educação Infantil & Março/2016 & Março/2017 \\
\hline
\end{tabular}

Quadro 1: Identificação das acadêmicas e de seus objetos de estudo no TCC.

Fonte: O autor, 2017.

Os nomes representados no quadro são fictícios para manter a integridade da identidade das alunas, cumprindo assim os princípios éticos da pesquisa. 


\section{Descrição E Análise De Dados}

\subsection{O Caso Da Futura Professora Aritmética}

\subsubsection{A Relação De Aritmética Com A Matemática Na Educação Básica}

As experiências positivas desta aluna foram nos anos iniciais do Ensino Fundamental, haja vista que mencionou ter boa relação com a disciplina até chegar à $5^{\mathrm{a}}$ série, período escolar em que suas dificuldades conceituais acentuaram-se e a fobia tomou conta do processo de aprendizagem, chegando a ter receio de comparecer às aulas de Matemática por sentir-se incapaz de aprender algo.

Sem dúvida as emoções desempenham um papel importante na aprendizagem dos alunos. Estudos no campo da Psicologia como, por exemplo, Wallon (1968), Piaget e Inhelder (2007) e Wadsworth (1992), afirmam que a inteligência e a afetividade são fatores inseparáveis, ou seja, para que o aluno desenvolva atitudes mais positivas que caracterizem processos de compreensão dos conteúdos escolares, é preciso que o ambiente da sala de aula seja reconfortante, mais aberto à comunicação, ao diálogo, as expressões e menos hostil, silenciador e castrador das manifestações espontâneas dos sujeitos.

Na afirmação de Aritmética, percebemos que o ambiente das aulas de Matemática, a partir de seu ingresso no Ensino Fundamental II, começou a ser intimidador. Em sua concepção, o aluno sofre influências do modelo formativo que vivencia na Educação Básica, pois ela menciona: "eu tinha lembranças boas, mas partir do momento que tive vivências ruins, passei a não gostar de Matemática, então assim, gostava de Matemática e de repente parei de gostar, isso pode influenciar minha prática, porque para mim o que fica é a última recordação e se em minha última recordação realmente não conseguia aprender Matemática, passei a não gostar mais dela, passei a não gostar por não conseguir resolver as questões, como irei trabalhar, ensinar meus alunos?!”.

Contudo, Aritmética, apesar do trauma adquirido com a disciplina a partir da $5^{\mathrm{a}}$ série, parece ter consciência da relevância de se libertar dos mitos e crenças negativas da aprendizagem matemática, dado importante para problematizar sua futura atuação como docente. Reconhecer suas limitações e buscar formas alternativas de sanar as dificuldades tanto conceituais quanto pedagógicas é o primeiro passo para a mudança de atitude e para aumentar 
a autoeficácia em Matemática.

\subsubsection{A Relação De Aritmética Com A Matemática No Ensino Superior}

Ingressar na Pedagogia foi desejo e não falta de opção. Essa foi a afirmação durante a entrevista, ainda mais pelo fato de Aritmética ter sido funcionária do setor administrativo de uma escola particular na região de Itaquiraí, interior do Estado de Mato Grosso do Sul - MS.

Neste ambiente escolar, algumas vezes, ela precisou assumir as turmas de Educação Infantil para suprir a falta de professores e, a própria direção, observou seu potencial para à docência, conforme esclarece: “(...) ela [se referindo à diretora] percebia meu comportamento como professora em partes e chegou e me chamou para conversar e falou que deveria fazer Pedagogia (...) me identifiquei muito então e não associe a Pedagogia com a Matemática, mas, sim, ao contato com as crianças que era o que eu tinha até então".

Ao ser questionada como se sentiu quando soube que no curso para o qual entrara (Pedagogia) haveria disciplinas relacionadas à Matemática, em resposta as lembranças negativas, oriundas da Educação Básicas, foram rememoradas inicialmente e teve uma reação aversiva, haja vista as experiências anteriores com essa disciplina, mas, aos poucos, foi percebendo que poderia aprender uma nova forma de ensinar os seus futuros alunos.

Enquanto professores formadores, vivemos constantemente o desafio de contribuir para a aprendizagem de um grupo de alunas/futuras professoras que um dia terão de ensinar aquilo que nem sempre aprenderam, dado este que nos coloca numa posição de destaque e aponta para a relevância de pensar quem é o professor formador de professores. Quem somos nós? Qual atividade temos direcionado no sentido de "libertar" as alunas destas amarras e conflitos gerenciados pela relação afetiva com o objeto de estudo (Matemática)?

Grande parte das dificuldades dos sujeitos (futuros professores) pode ser amenizada se no curso de Pedagogia tentarmos aproximar mais as alunas das perspectivas teóricometodológicas mais atuais que colocam a importância do aluno ser protagonista do processo de ensino/aprendizagem de conceitos na escola, como também da tendência metodológica da organização do trabalho pedagógico a partir da comunicação matemática e da resolução de problemas, elementos estes fundamentais para fazer com que o aluno pense e não apenas dê respostas certas, como temos acompanhado ao logo das propostas de reformas para o ensino da Matemática escolar no Brasil. Para tal, seria aspecto primeiro termos professores formadores de professores com uma trajetória de formação acadêmico-profisssional ligada à Educação Matemática e que fossem responsáveis pelas disciplinas de metodologias do ensino desta área 
do conhecimento, o que infelizmente não é uma realidade presente em cursos de Pedagogia em nosso país.

\subsubsection{A Relação De Aritmética Com A Matemática Durante A Pesquisa De Trabalho De Conclusão De Curso}

A investigação proposta para seu TCC teve como base identificar o que as professoras da Educação Infantil (pré-escola) ensinam sobre números às crianças pequenas. Para este fim, adotou uma abordagem metodológica, no campo da pesquisa qualitativa, de caráter descritivoanalítico em que a observação participante e a entrevista semiestruturada foram instrumentos centrais para coleta de dados junto às duas docentes atuantes em Centros Integrados de Educação Infantil (CIEI's) da rede municipal.

A escolha e delimitação do problema de pesquisa teve influência de dois fatores presentes na trajetória acadêmica de Aritmética: a) sua vinculação ao PIBID do curso de Pedagogia e; b) as atividades desenvolvidas no contexto da disciplina "Fundamentos e Metodologias do Ensino de Matemática I" (disciplina responsável pela organização do trabalho com a Matemática na Educação Infantil).

Não há como negar a influência positiva que Aritmética sofreu a partir de seu contato com as perspectivas teóricas para o ensino de Matemática, isso tanto no contexto da disciplina de formação básica no curso quanto no programa de iniciação à docência, ambos reiterados em vários momentos da narrativa.

O papel das leituras sobre o assunto foi importante para a ampliação de seu repertório de saberes e práticas, uma vez que, destaca, ao falar de sua pesquisa de TCC, o quanto o ato de ler tem se constituído como recurso para lidar com suas limitações específicas e didáticas: "me agrada bastante tudo que estou lendo porque minha dificuldade parece ficar menor cada vez que avanço no processo de constituir um referencial teórico para a pesquisa, pesquiso o que as professoras ensinam sobre números na Educação Infantil e ampliar as possibilidades de trabalho para além dos aspectos cardinais do número elou da estrutura do sistema de numeração decimal, é algo importante que tenho aprendido com os autores, ou seja, pensar o número na perspectiva do uso social, suas funções e procedimentos, enfim, é algo que tenho aprendido".

Na pesquisa de TCC, Aritmética elaborou um quadro que relaciona as possibilidades de trabalho com números na pré-escola a partir de uma análise interpretativa entre os objetivos 
para o ensino de "números e sistema de numeração" presentes no Referencial Curricular Nacional para a Educação Infantil (BRASIL, 1988) e as recomendações de Lorenzato (2006), exercício este que possibilitou compreender melhor em quais momentos da observação com as professoras de sua pesquisa poderiam ser explorados aspectos para além de contar e/ou trabalhar as noções aritméticas inicias na infância.

Durante as orientações, esta futura professora mostrou-se envolvida com a investigação e motivada para pensar em como o número poderia ser apresentado às crianças da pré-escola no sentido de colocá-las a pensar seus diferentes usos e funções.

Em momento de orientação para a análise dos dados de seu estudo, identifiquei a autoanálise feita sobre seu desempenho e ainda a prática reflexiva sobre o direcionamento e operacionalização do percurso recorrido para a finalização do TCC. A percepção de que ainda está em fase de aprimoramento na pesquisa fora algo recorrente em seu discurso: "acredito que a partir do momento que eu tiver mais aprofundada, que eu ler mais, tiver mais contato, que eu me aprofundar, vou estar entendendo mais sobre o ensino de números na Educação Infantil, pode refletir e discutir mais sobre o assunto, temos sempre de estar estudando".

É possível destacar, a partir do que fora exposto, que o conhecimento teórico tem influência na constituição do repertório didático e ainda na mudança de atitude dos futuros professores. Nesse entendimento, a pesquisa na formação inicial ocupa um lugar de destaque na aprendizagem do futuro professor quando o coloca em movimento de reflexão sobre o processo de ensino e aprendizagem de determinada área do conhecimento.

\subsection{O Caso Da Futura Professora Simetria}

\subsubsection{A Relação De Simetria Com A Matemática Na Educação Básica}

Dentre todas as acadêmicas, o caso de Simetria aponta para traumas que implicaram fortemente no modo como esta futura professora poderia vir a conceber o ensino de Matemática. Suas experiências com a disciplina não foram tão boas, apesar de ter revelado gostar um pouco das aulas durante seu percurso escolar, mas, enfim, ocorrera um episódio que a marcou profundamente de forma negativa.

\footnotetext{
Nunca fui um gênio, mas eu gostava de estudar, eu sempre gostei, tenho um fato marcante com uma professora que ela era muito nervosa quando ensinava para a gente, ela jogava régua, apagador, mesmo assim a gente não compreendia, eu me lembro muito bem que algumas vezes tinha que desviar do apagador porque eu demorava um pouco para entender algumas coisas, mas eu sempre gostei de aprender.
} 
O excerto ilustra uma lembrança expressiva do modo como Simetria relacionou-se inicialmente com a Matemática na escola. De forma geral, a experiência compartilhada trouxe aspectos negativos associados a um ambiente de aprendizagem tenso em que o discurso e prática do professor ocupava o protagonismo do processo educativo, ou seja, aos alunos competia seguir os passos sugeridos para o "bom" direcionamento da aula, caso contrário seriam "punidos".

Chamo à atenção para o fato de que, conforme destaca Nacarato (2010), as dificuldades das estudantes de Pedagogia estão atreladas, muitas vezes, as marcas deixadas pela Matemática escolar durante a trajetória que gera bloqueios de aprendizagem a partir de conflitos com a disciplina.

Neste cenário, a prática dos professores que Simetria teve diz muito sobre a forma como aprendeu: "só lembro do quadro mesmo, o quadro, giz, que vinha material diferente só quando utilizávamos a régua, o que era raro, não lembro de atividades práticas em si, era muito assim, o quadro e atividades individuais, não tinham atividades em grupo, em dupla, nem nada, sempre cada um em sua carteira e o profissional lá na frente explicando, às vezes quando a gente demorava muito para compreender, ela [a professora] chamava na mesa dela para tentar ensinar alguma coisa, mas era bem tenso isso".

A relação que o sujeito cria com o objeto de ensino depende de uma série de fatores estabelecidos anteriormente aos processos cognitivos propriamente ditos em que, dentre eles, o lado afetivo cumpre um papel primordial na confiança para aprender Matemática. Em outras palavras, a postura do professor frente ao modo como organiza e desenvolve sua aula pode representar motivação e/ou predisposição dos estudantes para aprender ou não algo.

\subsubsection{A Relação De Simetria Com A Matemática No Ensino Superior}

Simetria é formada em Química, ou seja, antes de ingressar no curso de Pedagogia já possuía uma formação de nível superior. Embora suas experiências com a Matemática na escola não tenham sido positivas, ir para a área pedagógica não representou um ato de fugir das Ciências Exatas, ao contrário, para essa futura professora a escolha significou uma importante complementação para sua prática e atuação.

Em sua concepção, foi uma forma de contemplar déficits formativos da primeira licenciatura, uma vez que percebeu que sabia muitas coisas, mas tinha certa dificuldade em ensinar os seus alunos, tal como a professora que relatou ter na Educação Básica. 
Para ela: "tenho outra visão de como a criança aprende em alguns momentos, de como eu tenho que me posicionar para ensinar, porque eu ensinar da forma como aprendi enquanto aluna no ensino fundamental e médio, vi que isso não dá certo, em minha atuação, a criança perguntava e eu recorria à lousa novamente, sempre da mesma forma para explicar e refletindo vi que estava fazendo o mesmo que vivenciei, dai pensei vou fazer Pedagogia, quero mudar".

Saber que no curso teria aspectos do ensino de Matemática trouxe à tona algumas angústias e lembranças negativas para Simetria, pois sentia que poderia passar novamente pelas mesmas dificuldades quando aluna.

\subsubsection{A Relação De Simetria Com A Matemática Durante A Pesquisa De Trabalho De Conclusão De Curso}

A investigação proposta por Simetria teve como objetivo compreender como a Geometria é abordada na Educação Infantil, especificamente, buscou-se relatar causas e consequências de seu abandono desde a pré-escola, pois em atividades de estágio obrigatório neste segmento de ensino, a acadêmica percebeu que as atividades relacionadas a essa área foram pouco exploradas pelas professoras, embora houvesse momentos propícios para o desenvolvimento do pensamento geométrico. Para este fim, recorreu-se a dados de um estudo de natureza qualitativa em que a observação das aulas e a entrevista semiestruturada foram essenciais para atingir os objetivos.

Ao observar questões do estágio, identificou um problema a ser tratado: razões da não abordagem da geometria com crianças da Educação Infantil. Assim, para além dos aspectos conceituais e pedagógicos da Matemática escolar, desenvolver e incentivar a prática de investigação em Educação Matemática precisa ser um dado valorizado no contexto da formação dos futuros professores, pois desenvolver uma vertente de reflexão sobre o ensino dos conteúdos matemáticos pode representar ainda um avanço nos princípios formativos e que poderá levar o docente a ter maior contato com as recomendações específicas da área.

A investigação em Matemática coloca o aluno, futuro professor, numa posição de destaque ao ter, com a experiência do trabalho e conclusão de curso, que pensar e redefinir práticas educacionais em sala de aula. A cada etapa do TCC, verificam-se novos aprendizados, lições e, conforme destacam Longo, Hanita e Queiroz (2017, p. 18), “[...] uma ascensão da pesquisa com postura investigativa da prática e, da prática docente dialogada com a pesquisa, o que reforça a necessidade de continuidade e de outras iniciativas do gênero". 
No caso de Simetria, o aprofundamento em referenciais teóricos sobre o ensino de Geometria trouxe o entendimento de que é necessário explorar, inicialmente, as relações espaciais das crianças para, posteriormente, trabalhar os aspectos dos atributos definidores das formas geométricas, o que sem a aproximação com a literatura especializada na temática não seria possível.

As leituras ainda levaram-na a reconhecer a importância do conhecimento teórico para a constituição da futura prática profissional em Geometria, ao afirmar que "ela [referindo-se a leitura] é formativa, isso para mim ela é formativa, ela me ajuda a pensar minha prática, acho que o tempo todo, sempre que eu tenho alguma coisa para fazer, trabalhar, direcionado em relação a esse tema da Matemática [falando da Geometria] eu sei onde buscar pelo menos, de repente não sei bem tudo ainda, mas sei onde busco, o que eu leio, como eu tenho que organizar os pensamentos depois da leitura, tem sido muito formativo esse processo de investigar o ensino de geometria, tive muito aprendizado de como trabalhar, tem sido bem importante para desenvolver mais confiança em trabalhar esse conteúdo com meus futuros alunos".

\section{Considerações Finais}

\footnotetext{
Mudou bastante minha postura porque agora eu tenho esse entendimento, agora eu conheço mais sobre o conteúdo, então, minha postura modificou muito com a pesquisa. Aritmética.

O TCC ampliou muito minha visão em relação à Matemática, ampliou mais ainda meus conhecimentos. Simetria.
}

Os casos descritos e analisados nesta investigação revelam a potencialidade da pesquisa em Educação Matemática em um curso de licenciatura em Pedagogia de uma universidade pública em que as estudantes se envolveram em um processo formativo promissor ao se colocarem em posição de refletir sobre o ensino e organização do trabalho pedagógico a partir de objetos de estudo de seus respectivos trabalhos de TCC's.

Os resultados de cada caso trouxe o entendimento de que as emoções ocupam um lugar de destaque na aprendizagem matemática de futuras professoras, o que abre uma agenda de pesquisa para próximas investigações no âmbito da Psicologia da Educação Matemática interrelacionada com a formação docente, haja vista a necessidade de compreender em que medida as experiências negativas, da Educação Básica, quando rememoradas no contexto da formação inicial podem ou não influenciar processos de predisposição à aprendizagem do adulto e/ou gerar bloqueios, aspecto este ainda em aberto com a finalização do estudo desenvolvido neste pós-doutorado. 
Pesquisar características do trabalho com este campo, durante o curso de Pedagogia, oportunizou as acadêmicas a percepção de suas limitações e a busca por modos de superação das dificuldades durante o desenvolvimento dos $\mathrm{TCC}^{\prime} \mathrm{s}$, esse movimento foi importante para a percepção de que o professor que ensina Matemática precisa articular sua prática em sala de aula às recomendações da literatura especializada, pois existe uma gama de possibilidades de organização das práticas com base nos princípios específicos de cada conteúdo.

A experiência deste estudo permitiu-me reforçar a necessidade de articular a pesquisa sobre o ensino no contexto da formação docente e ampliou o universo a ser pesquisado apontando questões ligadas à necessidade de estender esta proposta com uma nova intenção de estudos, de caráter longitudinal, para compreender as atitudes de professoras iniciantes em relação à Matemática. Além disso, trouxe novas inquietações que passarão a fazer parte do repertório de indicadores para melhoria de minha própria prática em sala de aula, na formação inicial de professores, como também na atuação enquanto orientador de outros trabalhos de conclusão de curso, dissertações e teses em programas de pós-graduação da instituição em que leciono.

\section{Referências}

AIKEN, L. R. Attitudes toward Mathematics. Review of Educacional Research, vol. 40, n.4, p. 551$596,1970$.

ARDILES, R. N. de. Um estudo sobre concepções, crenças e atitudes dos professores em relação à Matemática. 2007. 268 f. Dissertação (Mestrado em Educação). Faculdade de Educação, Universidade Estadual de Campinas, UNICAMP. Campinas: SP.

BANDURA, A. Social foundations of thought and action: a social cognitive theory. Englewood Cliffs, N. J.: Prentice-Hall. 1996.

BRITO, M. R. F. de. Um estudo sobre as atitudes em relação à Matemática em estudantes de $\mathbf{1}^{\mathbf{0}} \mathbf{e}$ $2^{\mathbf{0}}$ graus. 1996. 383 f. Tese (Livre Docência). Faculdade de Educação, Universidade Estadual de Campinas, UNICAMP. Campinas: SP, 1996.

CURI, E. Formação de professores polivalentes: uma análise de conhecimentos para ensinar Matemática e de crenças e atitudes que interferem na constituição desses conhecimentos. 2004. 278 f. Tese (Doutorado em Educação Matemática). Pontifícia Universidade Católica de São Paulo, PUC/SP. São Paulo: SP.

DOBARRO, V. R. Solução de problemas e tipos de mente matemática: relações com as atitudes e crenças de autoeficácia. 2007. 229 f. Tese (Doutorado em Educação). Faculdade de Educação, Universidade Estadual de Campinas, UNICAMP. Campinas: SP. 2007.

DOBARRO, V. R.; BRITO, M. R. F. Atitude e crença de autoeficácia: relações com o desempenho em Matemática. Educação Matemática Pesquisa, v.12, n. 2, p. 199-220, 2010. Disponível em: < http://revistas.pucsp.br/index.php/emp/article/viewFile/2180/3303 >, Acesso em: 04, jun. 2016. 
GONÇALEZ, M. H. C. de C. Atitudes (des)favoráveis com relação à Matemática. 1995. 147 f. Dissertação (Mestrado em Educação). Faculdade de Educação, Universidade Estadual de Campinas, UNICAMP. Campinas: SP.

LONGO, C. A. C.; HANITA, M. Y.: QUEIROZ, P. H. A pesquisa na graduação. In: LONGO, C. A. C.; HANITA, M. Y.: QUEIROZ, P. H. (Orgs.). A pesquisa na formação inicial de professores. São Carlos: Pedro \& João Editores, 2017. p. 09-18.

LORENZATO, S. Educação Infantil e percepção matemática. Campinas, SP: Autores Associados, 2006.

MARQUESIN, D. F. B.; NACARATO, A. M. Narrar a experiência e (trans)formar-se: o caso de uma professora diante do desafio de aprender a ensinar geometria. Interacções N. 18, PP. $54-75$ (2011).

Disponível em: < http://revistas.rcaap.pt/interaccoes/article/view/459/413 > , Acesso em: 30, mai. 2016.

MONTEIRO, C.A. formação para o ensino da Matemática na perspectiva da ESE de Lisboa. In: SERRAZINA, L. (org.). A formação para o ensino da matemática na Educação Pré-Escolar e no 1. ${ }^{\circ}$ ciclo do Ensino Básico. Lisboa/Porto, Inafop. 2001.

MORAES, M. S. S.; PIROLA, N. A. Atitudes positivas em relação à Matemática. In: BRASIL. Secretaria de Educação Básica. Diretoria de Apoio à Gestão Educacional. Pacto Nacional pela Alfabetização na Idade Certa. Alfabetização matemática na perspectiva do letramento. Caderno 07/Ministério da Educação, Secretaria de Educação Básica, Diretoria de Apoio à Gestão Educacional. - Brasília: MEC, SEB, 2015.

MORON, C. F. Um estudo exploratório sobre as atitudes e as concepções dos professores de educação infantil em relação à Matemática. 1998. 148 f. Dissertação (Mestrado em Educação). Faculdade de Educação, Universidade Estadual de Campinas, UNICAMP. Campinas: SP.

MOURA, A. R. L. de. Conhecimento matemático de professores polivalentes. Revista de Educação PUC - Campinas, n. 18, pp. 17-23, jun. 2005. Disponível em: $<$ http://periodicos.puccampinas.edu.br/seer/index.php/reveducacao/article/view/243/226 $>$, Acesso em: 02, jun. 2016.

NACARATO, A. M. Narrar a experiência docente... em processo de (auto)formação. In: GRANDO, R. C.; TORICELLI, L.; NACARATO, A. M. (Orgs.). De professora para professora: conversas sobre iniciação matemática. São Carlos: Pedro \& João Editores, 2008, pg. 143- 159.

NACARATO, A. M.; MENGALI, B. L. da S.; PASSOS, C. L. B. A matemática nos anos iniciais do Ensino Fundamental: tecendo fios do ensinar e do aprender. Belo Horizonte: Autêntica, 2009.

NACARATO, Adair M. A formação matemática das professoras das séries iniciais: a escrita de si como prática de formação. Bolema, Rio Claro, v. 23, n. 37, p. 905-930, 2010. Disponível em: $<$ http://www.redalyc.org/pdf/2912/291221915004.pdf $>$, Acesso em: 03, jun. 2017.

PIAGET, J.; INHELDER, B. A psicologia da criança. Tradução Octavio Mendes Cajado. Rio de Janeiro: Difel, 2007.

PIROLA, N. A.; JASINEVICIUS, F. P. M.; SANDER, G. P.; SILVA, G. A. da.; MORAIS, J. A. R. dos S.; SOUZA, P. P. F. da C.; YAMADA, T. R. U. Atitudes em relação à Matemática: contribuições das pesquisas em Psicologia da Educação Matemática. In: JORGE, M.; REIS, M. L.; MAGNONI, M. da. G. M. (orgs.). Cadernos de docência na educação básica IV: as experiências da docência - São Paulo : Cultura Acadêmica, 2015

RABELO, E. H. Textos matemáticos: produção, interpretação e resolução de problemas. 3ed. RJ: Vozes, 2002 
SERRAZINA, L. A formação para o ensino de matemática: perspectivas futuras. In: SERRAZINA, L. (org.). A formação para o ensino da matemática na Educação Pré-Escolar e no 1. ${ }^{\circ}$ ciclo do Ensino Básico. Lisboa/Porto, Inafop. 2001.

SOUZA, L. F. N. I.; BRITO, M. R. F. Crenças de autoeficácia, autoconceito e desempenho em matemática. Estudos de Psicologia, v. 25, n. 2, Campinas, 2008. Disponível em: < http://www.scielo.br/pdf/estpsi/v25n2/a04v25n2.pdf>, Acesso em: 05, jun. 2016.

THOMPSON, A. G. Teachers' beliefs and conceptions: a synthesis of the research. Handbook of research in mathematics teaching and learning. D. A. Grows, pp127-146. New York: Macmillan, 1992.

TORTORA, E.; SANDER, G. P.; PIROLA, N. A. Um estudo sobre as atividades em relação à Matemática com alunos do curso de Pedagogia. In: XI Encontro Nacional de Educação Matemática - XI ENEM - Educação Matemática: retrospectivas e perspectivas, Curitiba, PR - 18 a 21 de julho de 2013. Disponível em: < http://sbem.web1471.kinghost.net/anais/XIENEM/pdf/2462_1708_ID.pdf>, Acesso em: 06, jun. 2016.

WADSWORTH, B. J. Inteligência e afetividade da criança na teoria de Piaget. Tradução Esméria Rovai. São Paulo: Pioneira, 1992.

WALLON, H. A evolução psicológica da criança. Lisboa: Edições 70, 1968.

BRUNER, J. S. O processo da educação. São Paulo: Nacional, 1978. 